\section{O CONCEITO DE INVASÃO BIOLÓGICA NO ENSINO MÉDIO UTILIZANDO O JOGO “INVADE!”}

\author{
The concept of Biological Invasion in high school using "Invade!" game \\ El concepto de Invasión Biológica en la educación secundaria utilizando el juego \\ "Invade!"
}

Revista eletrônica Ludus Scientiae - (RELuS) | V. 2, N. 2, Jul./Dez. 2018.

\title{
AUTORES:
}

WAIRA SARAVIA MACHIDA

ORCID 0000-0002-6479-1652

${ }^{1}$ Universidade de

Brasília (UNB)

\section{Resumo}

A compreensão dos problemas ambientais auxilia na formação de cidadãos responsáveis com seu meio. Esta temática pode ser abordada no ensino básico, porém diversos problemas são negligenciados no currículo escolar. A Invasão Biológica (IB) é pouco abordada nas escolas e diante a complexidade do tema, o uso de jogos educativos pode facilitar seu ensino. Nosso objetivo foi propor e avaliar o potencial do jogo educativo "Invade!" no processo de aprendizagem do conceito de IB dos alunos de primeiro ano do ensino médio de uma escola pública do Distrito Federal. O jogo foi aplicado no Centro de Ensino Médio o3 do Guará. Dados de alunos, obtidos na aplicação do jogo, na produção textual sobre o jogo e em uma entrevista aberta grupal foram analisados. Verificamos que o jogo influencia no processo de aprendizado de IB por ser divertido e simples e que os alunos compreenderam as principais características da IB. O jogo se mostrou eficaz para o ensino de IB e permitiu o ensino não enviesado sobre as espécies exóticas invasoras.

Palavras-Chave: Invasão Biológica; Processo de ensino-aprendizagem; Jogo educativo; Educação lúdica.

\begin{abstract}
Understanding the environmental problems support the qualification of responsible citizens with their environment. Environmental problem could be learned in primary education, but several environmental problems are neglected in the school curriculum. The Biological Invasion (BI) is little approached in schools and given the complexity of the BI, the use of educational games can make teaching easier. Our objective was to propose and evaluate the potential of the "Invade!" didactic game in the process of learning of BI concept of the first year high school students of a public school in the Federal District. The game was applied at Guará High School o3. Data from students obtained in the game application, in the textual production on the game and an open group interview were analyzed. We verify that the game influences the learning process of BI because it is fun and simple and that he students understood the main characteristics of BI. The game proved to be effective for BI teaching and allowed non-skewed teaching on invasive alien species.
\end{abstract}

Keywords: Biological Invasions; Learning processes; Educational games; Ludic education.

\section{Resumen}

Entender los problemas ambientales ayuda a la formación de ciudadanos responsables con su medio. Este tema puede ser enseñado en la educación básica, pero diversos problemas ambientales son ignorados en el currículo escolar. La Invasión Biológica (IB) es poco abordada, pero su complejidad puede ser resuelta con el uso de juegos educativos. Nuestro objetivo fue proponer y evaluar el potencial del juego "Invade!" en el proceso de aprendizaje del concepto de IB de los alumnos del primer grado de un colegio público del Distrito Federal. El juego fue aplicado en el Centro de Ensino Médio o3 do Guará. Los datos de alumnos obtenidos en la aplicación del juego, en la producción textual sobre el juego y una entrevista abierta grupal fueron analizados. Verificamos que el juego influye en el proceso de aprendizaje de IB por ser divertido y simple y los alumnos entendieron las principales características de la IB. El juego es eficaz para la enseñanza de IB y permitió la enseñanza no sesgada sobre las especies exóticas invasoras.

Palabras clave: Invasión Biológica; Proceso de aprendizaje; Juego educativo; Educación Lúdica.
HILTON DE JESUS DOS

SANTOS $^{2}$

ORCID 0000-0002-1282-0685

Universidade de

Brasília (UNB)

ANA JÚLIA PEDREIRA ${ }^{3}$

ORCID 0000-0003-2124-1789

3 Universidade de Brasília (UNB)

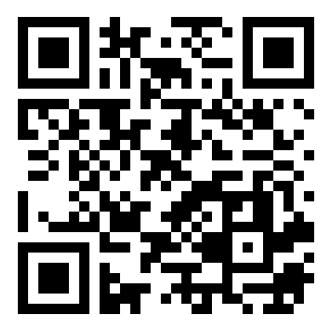

Para citar este artigo:

MACHIDA, W. S.; SANTOS, H. J.; PEDREIRA, A. J. O conceito de invasão biológica no ensino médio utilizando o jogo “invade!". Revista Eletrônica Ludus Scientiae, Foz do Iguaçu, v. 02, n. 02, p. 71-89, jul./dez. 2018. 


\section{INTRODUÇÃO}

Desde os anos de 1970, os problemas ambientais se tornaram prioridade na agenda das Nações Unidas, declarando como objetivo a melhora do meio ambiente e a formação de cidadãos reflexivos com atitudes de proteção e responsabilidade em relação aos ambientes naturais (BRASIL, 1972). No Brasil, os Parâmetros Curriculares Nacionais (PCN), na área de Ciências da Natureza, Matemática e suas Tecnologias, são documentos oficiais ainda utilizados e reconhecidos, que orientaram e sugerem aos docentes do ensino básico a abordagem dos problemas ambientais nas suas aulas (BRASIL, 200o). Para atingir este objetivo, o docente pode apresentar aos estudantes a ampla gama de problemas ambientais existentes, estimulando o desenvolvimento de competências sugeridas pelo PNC (BRASIL, 2002). Porém, observa-se que alguns temas específicos, mas não menos importantes, dentro dos problemas ambientais são frequentemente esquecidos no conteúdo escolar. Dentro destes, destaca-se a Invasão biológica (IB) que é pouco abordada no ensino básico.

A invasão biológica é um processo ecológico populacional, mediado pelo ser humano, no qual uma espécie atravessa diversos estágios ou barreiras, resultando na "invasão", que pode levar à perda de biodiversidade nativa, na modificação de processos ecossistêmicos e na diminuição de serviços ecossistêmicos (LEVINE et al., 2003; LOCKWOOD et al., 2007; PEJCHAR; MOONEY, 2009; PYŠEK et al., 2012). A IB permite que espécies exóticas, por meio do estabelecimento no local introduzido, tornese um agente de mudanças ameaçando a biodiversidade nativa local (CBD, 2018).

O conceito de invasão biológica (IB) utilizado neste trabalho segue a abordagem de Lockwood et al. (2007), sendo descrito como um processo ecológico, mediado pelo ser humano, no qual uma espécie atravessa diversos estágios ou barreiras, resultando na "invasão". A definição de IB por meio de processos possui três níveis: transporte, estabelecimento e dispersão. Os autores argumentam que a IB resulta em algum impacto, porém neste trabalho, por motivos didáticos, adicionamos uma quarta barreira para esclarecer as consequências que a introdução de espécies exóticas invasoras causadas no ambiente invadido. O resultado do impacto pode ser a introdução de uma espécie exótica invasora (EEI), entendida por uma espécie exótica que se estabelece no local introduzido, tornando-se um agente de mudança e ameaçando a biodiversidade nativa local (CBD, 2018).

A publicação do Informe Nacional sobre Espécies Exóticas Invasoras, em 2005, incentivou a pesquisa nesta área, e assim, foi observado um aumento na quantidade de pesquisas, publicações científicas e Marcos Legais sobre a IB, porém o ensino desse tema foi pouco fomentado (ZENNI et al., 2016). Quando realizadas, as pesquisas em educação científica que abordam a IB têm se limitado à educação ambiental, utilizando o Caramujo-gigante-africano Achatina fulica Bowdich como modelo de estudo (SOUZA et al., 2007; PEREIRA et al., 2012; GROTT; MELLO, 2014; PECORA; MIRANDA, 2014; QUEIROZ et al., 2014; ALVES et al., 2017).

Um contraponto à abordagem da IB pela educação ambiental é a rotulação das EEI como vilãs. Isto acontece quando o conteúdo é focado no impacto negativo da espécie e em suas formas de remoção. Com o rótulo de vilã, os atos de remoção ou procedimentos de erradicação das EEI por civis podem acabar causando problemas ambientais, como eliminação de qualquer espécie que se assemelhe à EEI (BOAVENTURA et al., 2011; PECORA; MIRANDA, 2014). É importante destacar que a IB acontece a nível populacional, não sendo um atributo intrínseco da espécie em ambientes de ocorrência natural, porém têm a capacidade de causar impactos negativos após a introdução da espécie em ambientes novos por ação antrópica (SIMBERLOFF et al., 2013). Apesar de que a espécie cause impactos, temos que levar em conta que no início do século já era conhecido que aproximadamente $75 \%$ das EEI foram introduzidas no Brasil voluntariamente pelo ser humano (ROMAIS et al., 2003), logo a espécie em si não pode ser responsabilizada pelo impacto que causa ou causou.

Apesar dos problemas que podem ser causados dependendo da maneira em que a IB é abordada na escola, há uma lacuna nos métodos de ensino que abordem especificamente o conceito de IB. 
Dentre os vários recursos didáticos, o jogo e seu caráter lúdico tem o potencial de tornar o aprendizado mais prazeroso e motivador, criando assim uma afeição pelo tema estudado. $O$ jogo permite o aprendizado de conteúdos e o desenvolvimento de competências como a produção de investigação científica, comunicação de conhecimentos e socialização (BRASIL, 20oo; KISHIMOTO, 1996; CUNHA, 2012). Considerando tais vantagens, a aplicação de um jogo sobre conceitos de IB pode ser mais efetiva para o aprendizado dos alunos, além de ser um recurso que pode vir a incentivar os professores a abordarem este tema (CANTO; ZACARIAS, 2009, OLIVEIRA et al., 2015).

Diversos conteúdos específicos da Biologia são ignorados pelos docentes por suposta irrelevância, dificuldade de ensino, falta de tempo ou por não estarem incluídos no currículo escolar (OLIVEIRA et al., 2015). Uma das vantagens do jogo é a possibilidade do ensino de conteúdos específicos, sendo esse, um recurso alternativo que permite o ensino de tais conteúdos específicos de forma agradável e motivadora (CANTO; ZACARIAS, 2009), sem causar nos alunos nem docentes a impressão de que estão aprendendo conteúdos "inúteis" para sua formação. Dentre os diversos recursos didáticos, o jogo se destaca por auxiliar os alunos no desenvolvimento de diversas habilidades como ser a cooperação, produção científica, raciocínio lógico, interpretação, entre outros (FORTUNA 2003; NICOLA; PANIZ, 2016;). Sendo assim, a abordagem do conteúdo de IB por meio do jogo educativo pode ser eficaz no processo de aprendizado de conceitos do tema.

O presente estudo, ao propor um jogo original para o ensino conceitual da invasão biológica, traz uma abordagem diferente daquela apresentada nos artigos científicos citados anteriormente. Por não ter como objetivo a mudança de atitude, a probabilidade de produzir preconceitos sobre algumas EEI por seu status de invasora no país diminui. Assim, o objetivo deste trabalho é, portanto, propor e avaliar o potencial do jogo "Invade!" no processo de aprendizagem do conceito de invasão biológica, com alunos de primeiro ano do ensino médio de uma escola pública no Distrito Federal.

\section{MATERIAIS E MÉTODOS}

\section{O jogo “Invade!"}

O estudo foi realizado no Centro Educacional o3 do Guará - DF (CED o3), comumente chamado "Centrão" do Guará. Esta escola foi inaugurada em 1974 e possui uma infraestrutura acolhedora para a comunidade escolar, estando vinculada à Coordenação Regional de Ensino (CRE) do Guará, Distrito Federal. Antes da realização da pesquisa, o professor da turma distribuiu aos alunos o Termo de Consentimento Livre Esclarecido (TCLE) que foi levado aos responsáveis.

A estrutura do jogo "Invade!" teve como base teórica o ensino construtivista, a qual permite que o aluno construa seu próprio conhecimento pela associação de conhecimentos prévios e conhecimentos novos (LIBÂNEO, 2001), já que o aprendizado de um conceito pode ser muito mais eficaz quando o aluno constrói pessoalmente o seu significado. Diante disso, o jogo trata de colocar o aluno como sujeito ativo na construção do conhecimento, por meio da elaboração de hipóteses que descrevam um fenômeno. Ao compreendê-la conceitualmente, é possível que os alunos percebam que, atualmente, há diversas espécies do nosso cotidiano que se encaixam neste contexto e comecem assim a refletir sobre nosso papel no planeta Terra e nos cuidados e responsabilidades que devemos ter.

O jogo "Invade!" é um jogo de tabuleiro que aborda o conceito de IB, idealizado e elaborado pelos autores deste trabalho. O objetivo do jogo é a construção do conceito de Invasão Biológica e Espécie Exótica Invasora por meio da formulação de hipóteses. O jogo consiste em ajudar a sua espécie a atravessar as "barreiras" da invasão que resultará na denominação da espécie em EEI. As regras do jogo estão detalhadamente escritas no Quadro 1. 
Quadro 1: Regras do jogo "Invade!".

\section{Invade! - Regras do Jogo}

Objetivos do jogo: Compreender o conceito de invasão biológica por meio da elaboração de hipóteses sobre as barreiras enfrentadas no processo de invasão pelas espécies invasoras.

Objetivos específicos:

- Entender que a invasão biológica atualmente é mediada pelo homem.

- Compreender que para ser classificada como espécie invasora, a espécie em questão precisa causar algum impacto ambiental, social ou econômico.

- Fazer uso de conceitos já aprendidos nas aulas de ecologia como ser nicho, dispersão, etc.

Material:

- Tabuleiro

- Peão (Peão de biscuit ou ficha impressa): 2 capins-gordura, 2 mosquitos da dengue, 2 pinheiros e 2 caramujos-gigantes-africanos. Serão usados pelos grupos no tabuleiro.

- Cartas barreiras: 4 tipos de cartas para cada barreira da invasão. (16 a cada dois grupos)

- Carta nota (5 por grupo)

- Ficha de hipótese: Ficha na qual os grupos escrevem suas hipóteses. (1 p/grupo)

- Ficha das espécies: Esta ficha dá uma orientação ao grupo sobre os atributos e a história da espécie escolhida. Uma ficha por grupo e deve ser igual à espécie escolhida. (1 p/grupo)

- Ficha gabarito: Cada grupo terá uma ficha gabarito de uma espécie diferente da sua. Esta ficha para orientação na avaliação. (1 p/grupo)

- Cronometro: Pode ser de qualquer tipo.

Forma de ganhar: Obtendo a maior quantidade de pontos (máximo 20 pontos) para chegar no final do tabuleiro. O grupo que tiver a posição no tabuleiro mais próxima ao Fim é o ganhador.

- O jogo pode ser realizado de uma a duas horas.

- Podem ser separados até oito grupos por jogo com aproximadamente cinco pessoas por grupo. É sugerido que os grupos não sejam compostos por mais de seis pessoas para que todos possam participar do jogo.

- É sugerido que no total tenha um número par de grupos, pois dois grupos terão a mesma espécie.

- Cada dois grupos recebem 16 "Carta barreira" (4 p/barreira) e cada grupo recebe cinco "Carta nota” (com numeração de 1 a 5).

Modo de jogar: Serão no total quatro turnos para finalizar o jogo.

Os grupos (4 espécies, um par de grupo por espécie) iniciarão no mesmo local do tabuleiro (Inicio). Para poder avançar no tabuleiro, cada grupo precisa atravessar uma barreira da invasão formulando e escrevendo uma hipótese no local correspondente na "ficha de hipótese". A hipótese deve seguir os critérios especificados na "ficha de hipóteses" que lhe será entregue. Para formular a hipótese, cada grupo deve escolher pelo menos uma carta (dentre quatro) que corresponde à barreira e responder as questões da ficha de hipótese. Como cada dois grupos terão a mesma espécie, os grupos que possuem a mesma espécie compartilharão as quatro cartas de cada barreira o que impedirá que para a construção da hipótese a mesma carta seja utilizada pelos dois grupos. Assim, a competição acontecerá entre grupos da mesma espécie (intraespecífica) e não entre as diferentes espécies (interespecífica).

A hipótese deve ser formulada em cinco minutos e será cronometrada pelo professor ou responsável pela turma. Todos os grupos formularão as hipóteses ao mesmo tempo.

As hipóteses dos grupos que compartilham a espécie serão apresentadas em sequência e os dois grupos receberão uma nota. A avaliação será por meio de comparação das duas hipóteses propostas e será realizada pelos outros grupos que possuem espécies diferentes daquela que está formulando a hipótese. Para dar nota os grupos avaliadores devem utilizar a "Carta nota" e a nota final de cada barreira será dada pela média aritmética arredondada para cima da nota de todos os avaliadores. 
Os grupos avaliados poderão avançar no tabuleiro de acordo com a nota recebida, por exemplo, se a nota for quatro, o grupo avança quatro casas. O ganhador será aquele grupo que conseguir chegar mais próximo do "Fim".

Após o jogo terminar, é fortemente sugerido que haja uma roda de conversa sobre os conceitos aprendidos no jogo.

Fonte: Autora.

Dois grupos de alunos são designados à mesma espécie para simular uma corrida pelo "sucesso" da invasão (quem fizer maior número de pontos é o vencedor), totalizando oito grupos com dois peões de cada espécie. Para avançar no tabuleiro (Figura 1), as equipes devem formular hipóteses biologicamente corretas que permitam que a espécie atravesse a barreira. Os alunos deverão pensar e achar maneiras de atravessar as barreiras utilizando os materiais apresentados pelo jogo em suas cartas (Figura 2).

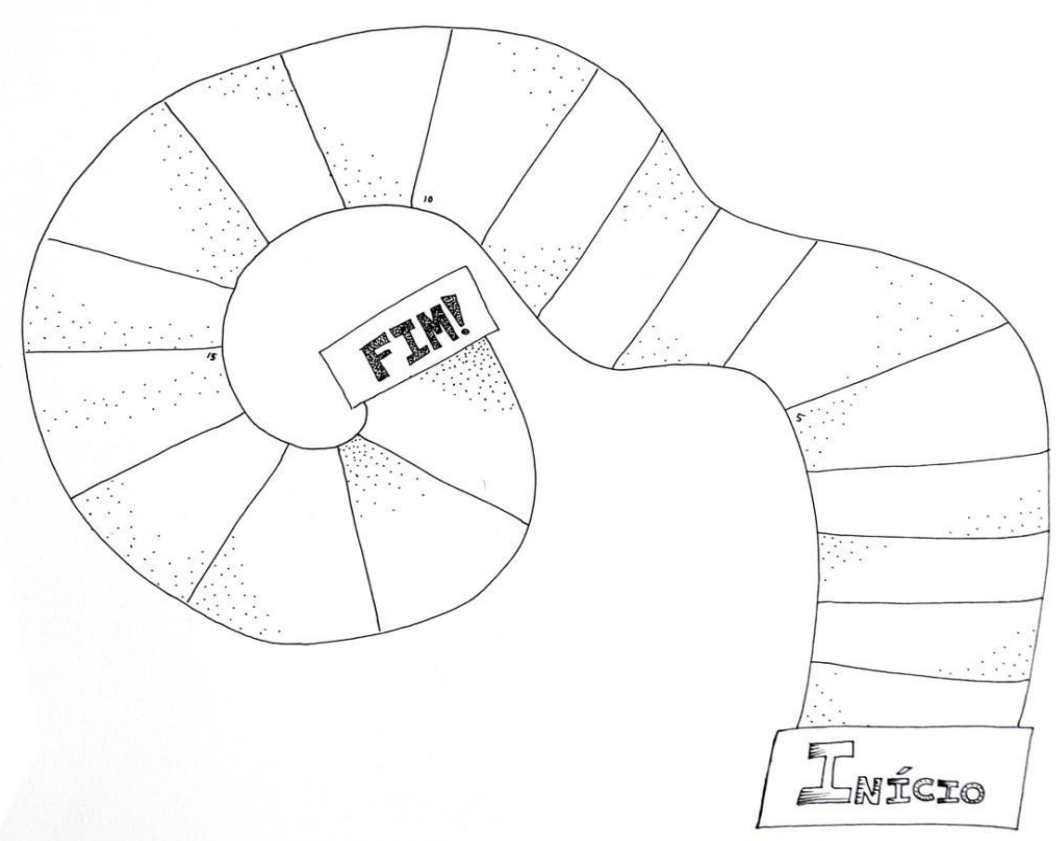

Figura 1: Tabuleiro do jogo “Invade!”. Fonte: Autora. 


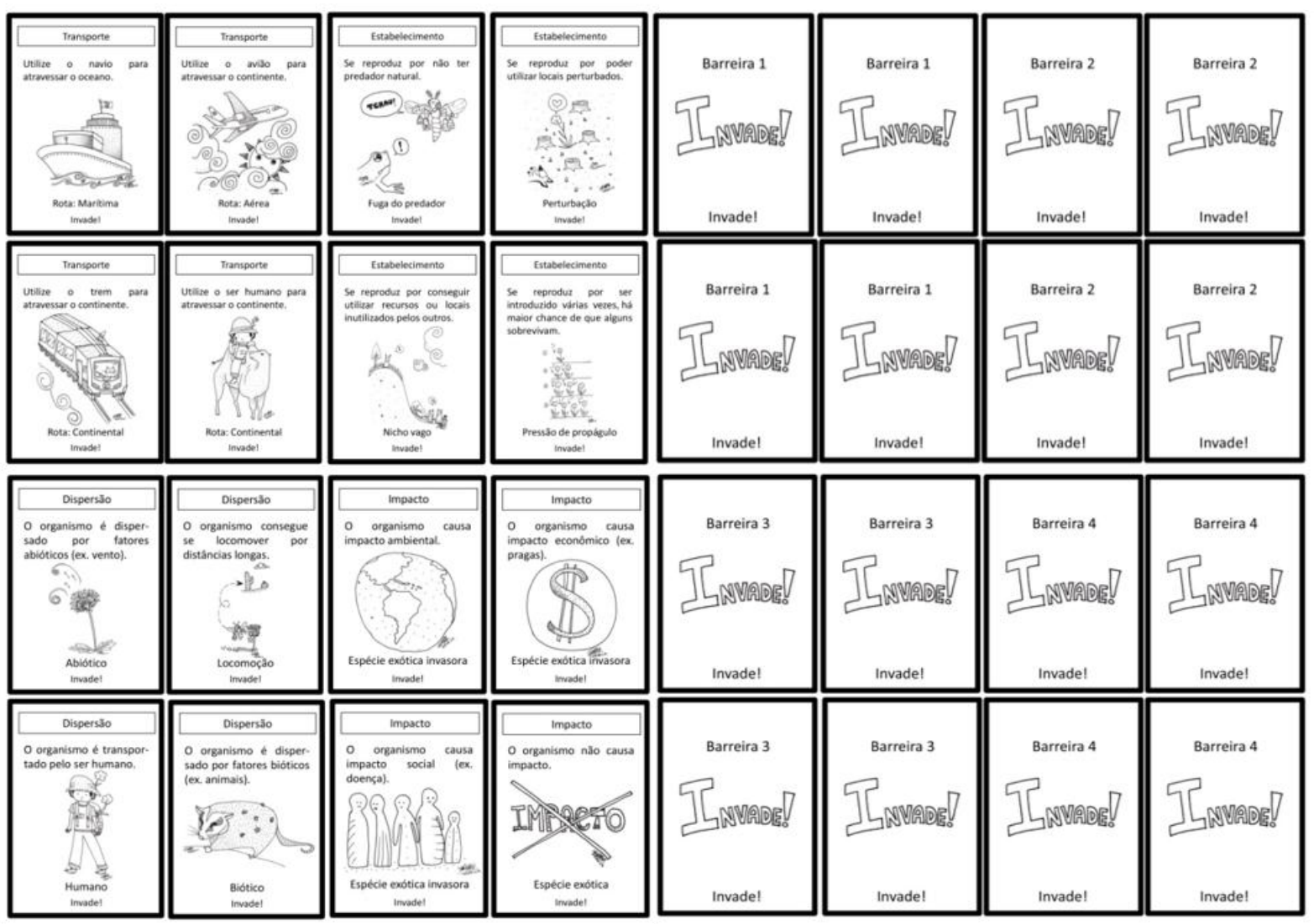

Figura 2: Frente e verso das cartas do jogo “Invade!" utilizadas para atravessar as quatro barreiras. Fonte: Autora.

As espécies utilizadas são o mosquito da dengue Aedes aegypti L., o caramujo-gigante-africano Achatina fulica Bowdich, o pinheiro Pinus sp. e o capim-gordura Melinis minutiflora P.Beauv. Para cada espécie, fichas com informações gerais sobre a espécie e fichas com o gabarito de cada espécie foram produzidos para auxiliar na formulação das hipóteses (Figura 3).
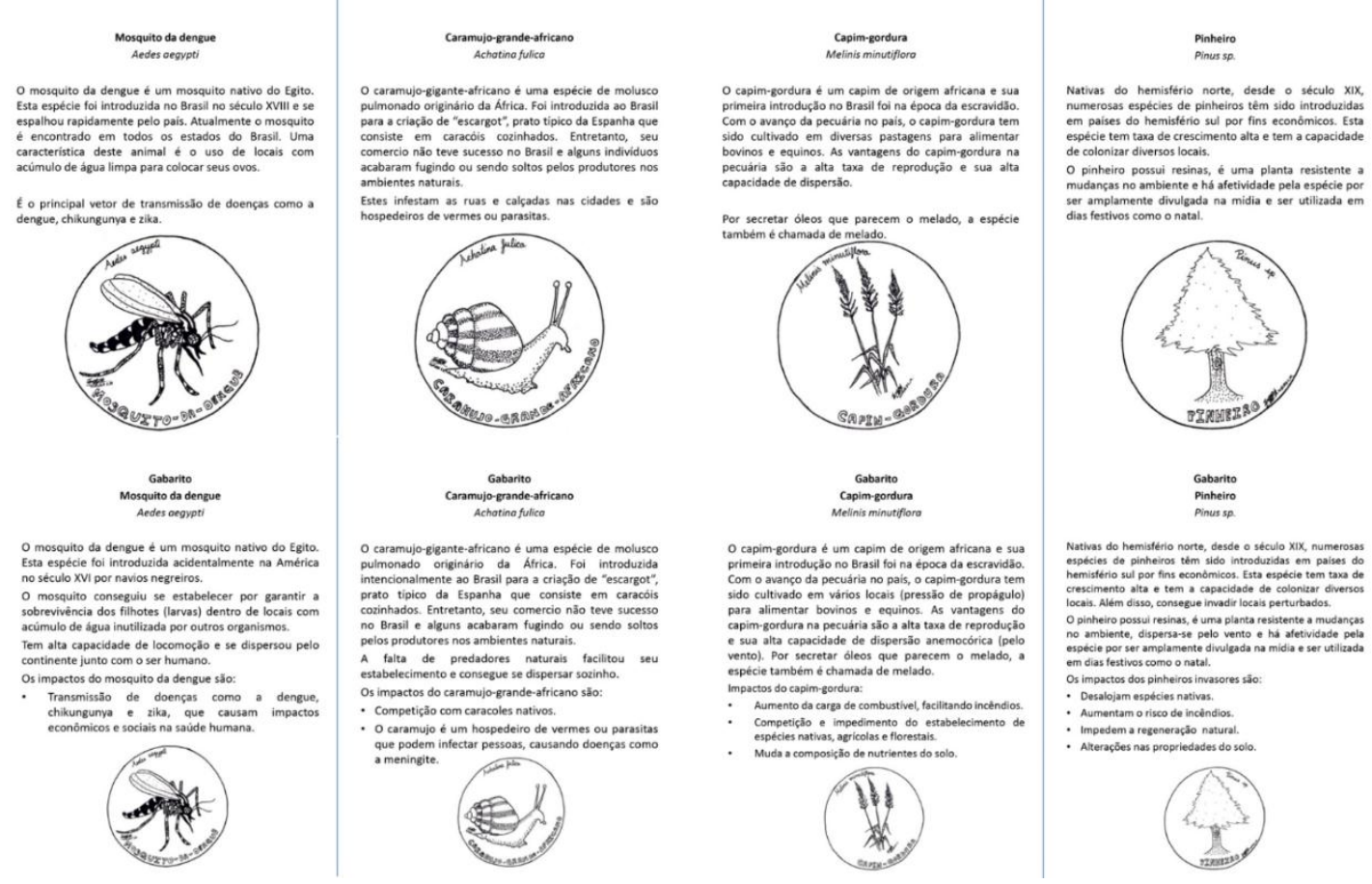
Figura 3: Ficha descritiva das espécies (cima) e fichas gabarito (baixo) do jogo “Invade!”. Fonte: Autora.

Foram delimitadas quatro barreiras da invasão: transporte, estabelecimento, dispersão e impacto. Estas são preenchidas na ficha designada no Quadro 2.

Quadro 2: Ficha entregue aos participantes do jogo “Invade!" para escrever as hipóteses formuladas.

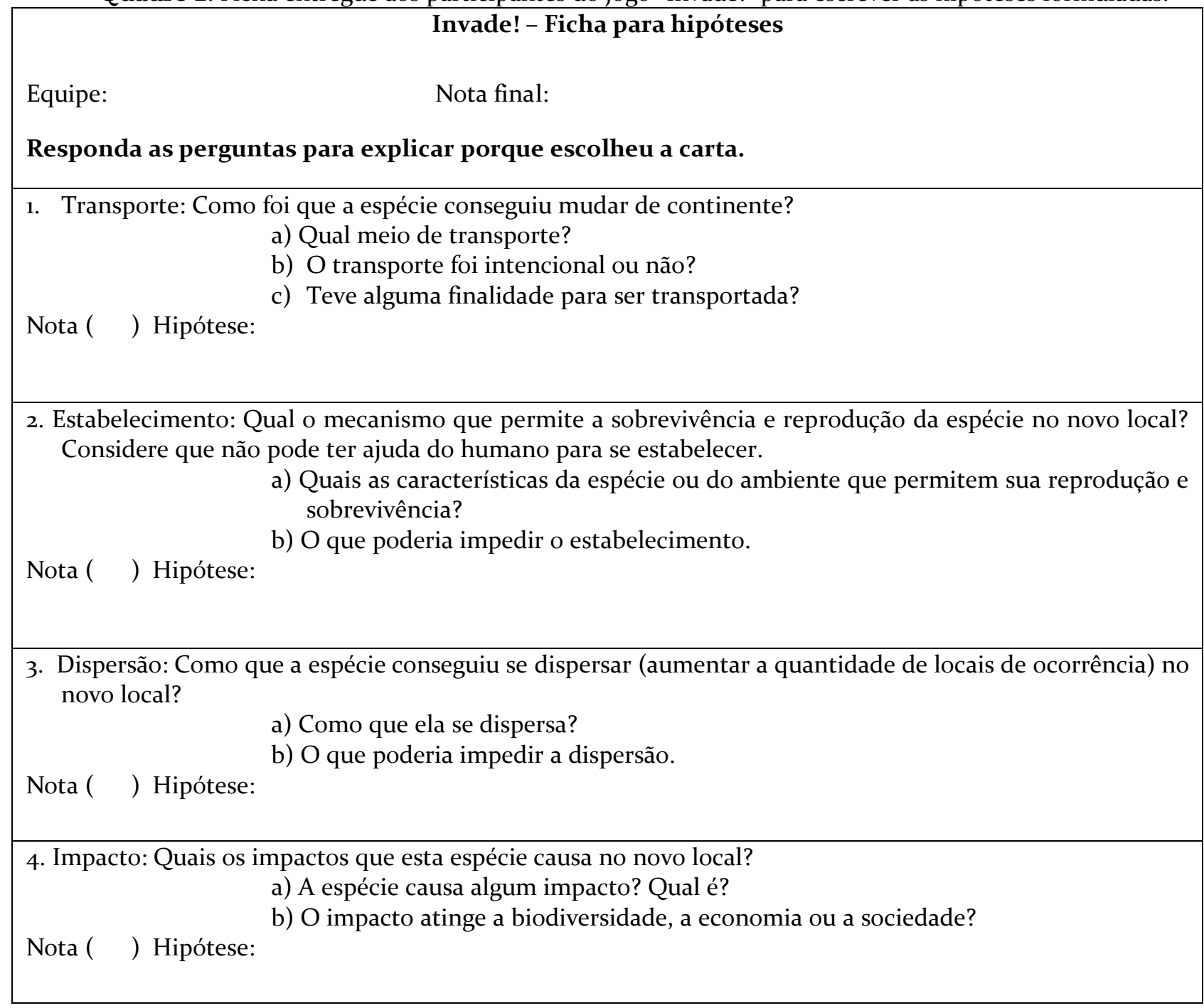

Fonte: Autora.

O transporte remete à rota e ao vetor de transporte pelo qual o organismo foi deslocado do seu local de ocorrência natural para o local colonizado. A rota seria o "caminho" percorrido entre o local de origem e de introdução e o vetor de transporte é a maneira pela qual o organismo é levado pela rota (MACK; LONSDALE, 2001). Esta barreira inicial é bastante influenciada pelo ser humano, pois historicamente, nossa espécie transporta outros organismos com ou sem intenção.

O estabelecimento é a formação de populações autossustentáveis das espécies que foram transportadas. Para serem autossustentáveis, as populações devem sobreviver e reproduzir sem ajuda do ser humano (CBD, 2018). Utilizamos algumas hipóteses do sucesso da invasão nas cartas para poder exemplificar como as espécies atravessam o obstáculo. A primeira hipótese é a pressão de propágulos, na qual prevê que o sucesso de invasão acontece pela introdução frequente desses propágulos (organismo ou partes dele que atuem como propágulos) (RAMULA et al., 2015). A segunda hipótese é a fuga do predador, que ocorre quando as populações de EEI no local colonizado não são controladas por predadores naturais (KEANE; CRAWLEY, 2002). 
A terceira hipótese sugere que a perturbação facilita e promove a IB (HIERRO et al., 2006). A quarta e última hipótese é o nicho vago, na qual a EEI aumenta seu valor adaptativo ao utilizar espaços com menor sobreposição de nicho com outros organismos (BRETON et al., 2005; GODOY et al., 2009). Estas hipóteses condizem com o conteúdo de ecologia necessário para serem compreendidas pelos alunos.

A dispersão é o processo pelo qual a população da espécie exótica aumenta sua distribuição, expandindo sua área de ocorrência e abundância (LOCKWOOD, et al., 2007). Essa acontece por fatores abióticos, bióticos ou pelo ser humano de forma intencional ou não intencional.

Finalmente, o impacto é entendido como resultado final da passagem das barreiras, porém não possui um conceito fechado por ter diversas interpretações. Em geral, é considerado impacto qualquer consequência que a EEI cause no local introduzido. Neste estudo, os impactos foram classificados em três grupos: ambiental, social e econômico. O impacto ambiental é qualquer mudança nos processos ecossistêmicos (SIMBERLOFF et al., 2013). Consideramos impacto econômico os danos econômicos associados às EEI e o impacto social os danos causados à saúde, cultura ou bem-estar humano. Os três tipos de impactos são fortemente relacionados, como por exemplo, a EEI ampulária-dourada, uma espécie de molusco gastrópode, causou eutrofização em águas purificadas do sudeste asiático, se alimenta de plântulas de arroz impedindo o plantio e deixa a água com odor, impedindo seu consumo pelo ser humano (PEJCHAR; MOONEY, 2009).

O layout do jogo "Invade!" inteiro é de autoria própria. Todas as ilustrações das cartas, peões para impressão e tabuleiro foram desenhados, digitalizados e montados. Os peões físicos foram criados utilizando biscuit e alguns outros peões foram ilustrados para impressão, para que a dificuldade de os criar em biscuit não desmotive qualquer pessoa que queira utilizar o jogo em sala de aula (Figura 4).
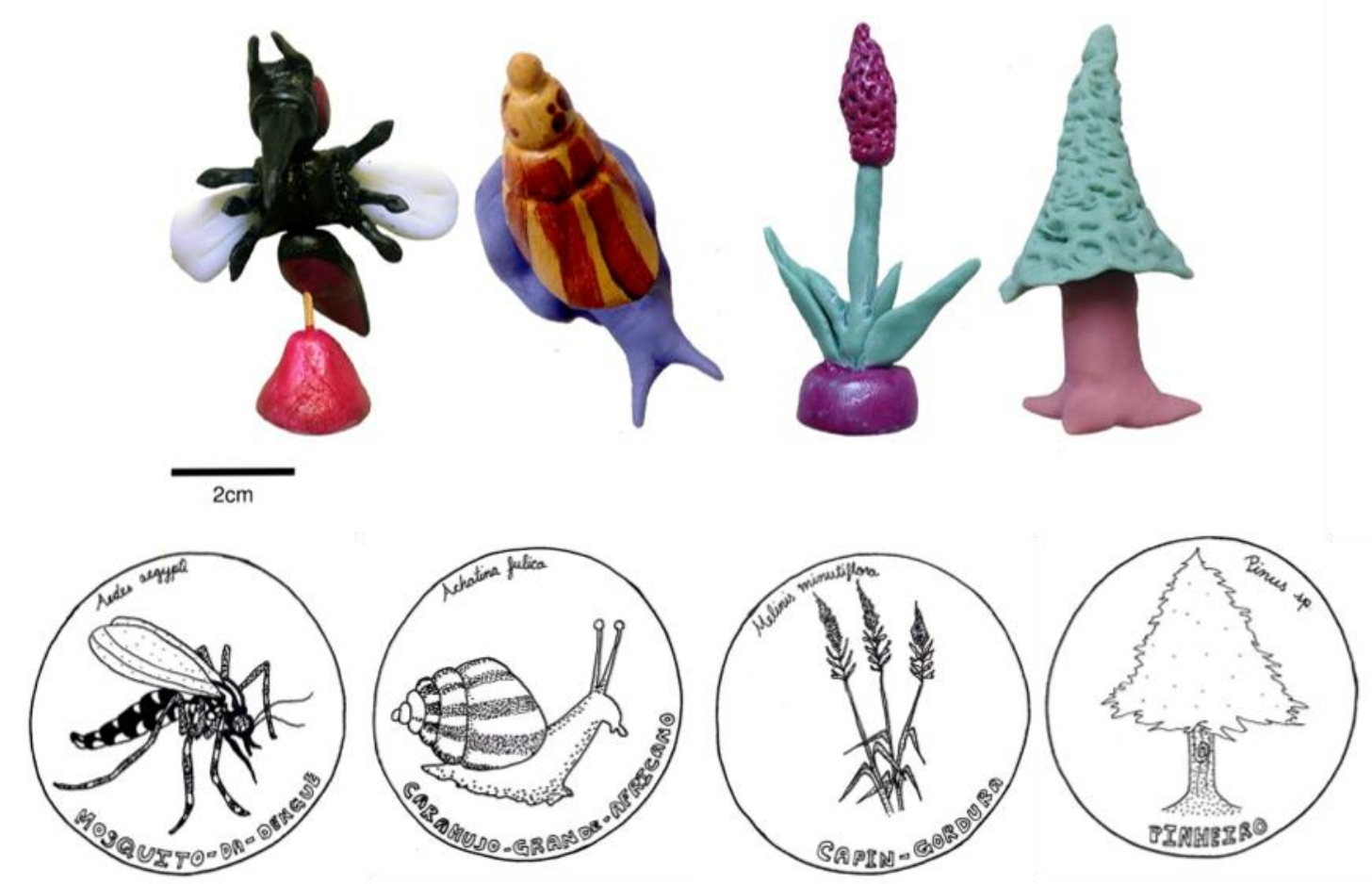

Figura 4: Peões criados com biscuit e peões para impressão do jogo “Invade!”. Fonte: Autora.

A competitividade entre os grupos foi pensada como uma tentativa de motivação para os alunos durante o jogo. Segundo Macedo (1995) a competição por si só não é má nem boa, no caso desse jogo a competição aconteceu tanto pelos grupos que escolheram a mesma espécie como entre todos 
os grupos, pois o ganhador foi aquele que conseguiu a melhor pontuação. Para receber a pontuação, os grupos com a mesma espécie foram comparados e avaliados pelos próprios colegas de outro grupo com outra espécie utilizando as cartas devidas (Figura 5). A avaliação das hipóteses pelos próprios participantes do jogo permitiu que não tivesse necessidade de um docente guiando o jogo, colocando assim o professor como um mediador, permitindo que, dessa forma, os jogadores pudessem ser sujeitos ativos durante todo o jogo.
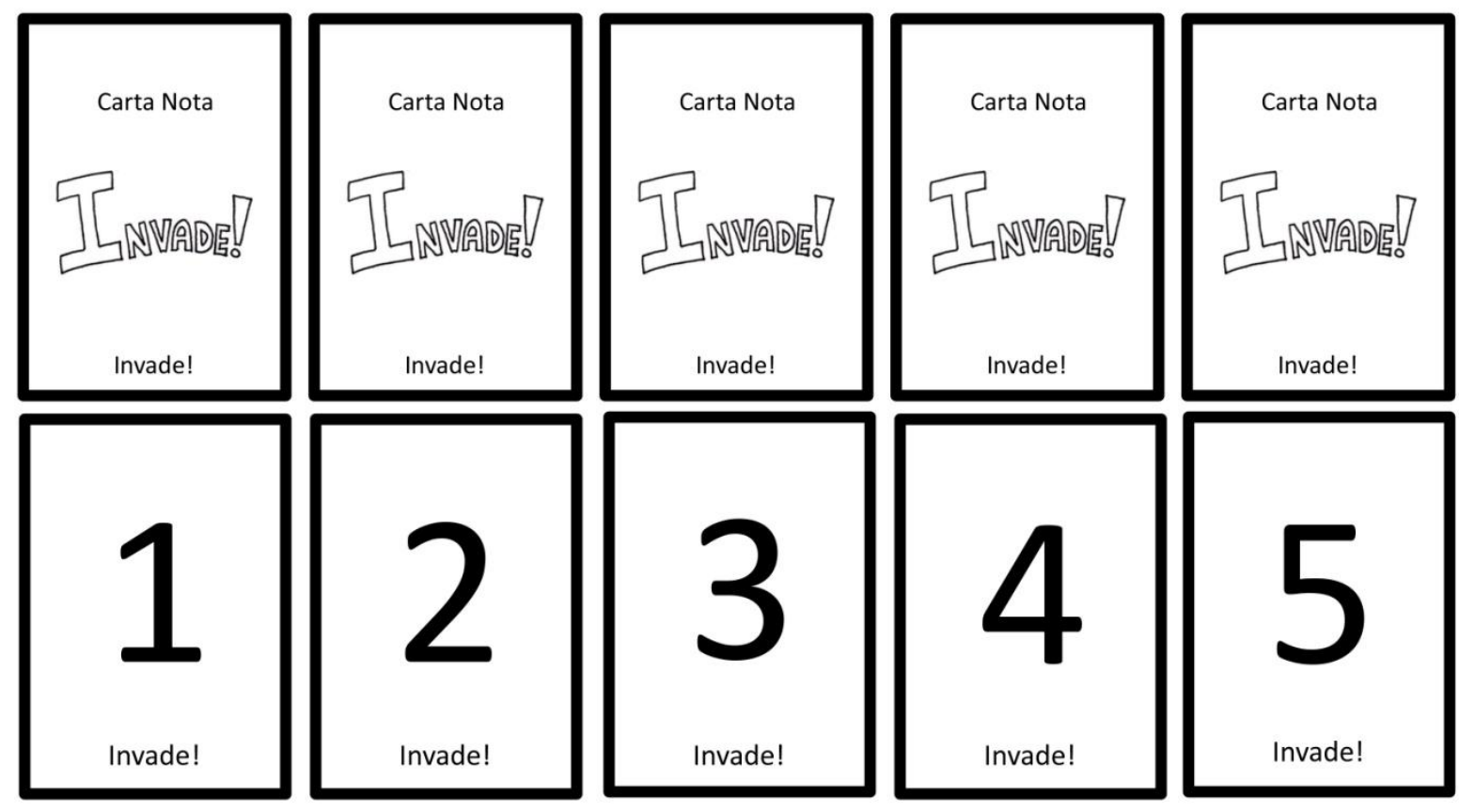

Figura 5: "Carta nota” utilizadas no jogo "Invade!" para a avaliação das hipóteses formuladas. Fonte: Autora.

\section{Coleta e análise de dados}

Apesar de apenas 22 alunos terem devolvido os TCLE, o jogo foi aplicado aos 32 alunos da turma do primeiro ano do ensino médio no primeiro semestre de 2018 (somente foram coletados dados dos 22 alunos que entregaram o TCLE). A turma foi encaminhada para o jardim da escola, local de aplicação do jogo. Nesse dia o horário do intervalo da escola foi expandido, o que impediu que o jogo fosse terminado, sendo esse interrompido e continuado na aula seguinte.

Logo após a aplicação do jogo no primeiro dia, mesmo esse não tendo sido terminado, foi pedido aos alunos que realizassem uma produção textual a partir de um roteiro (Quadro 3). Essa atividade teve como objetivo conhecer as experiências, impressões, sugestões e críticas sobre o jogo, até o ponto em que havia sido jogado. O produto foi analisado conforme a metodologia de análise de conteúdo de Moraes (1999). Os textos foram separados em três categorias, sendo estes: conceitual, aprendizado e ludicidade. As hipóteses levantadas pelos alunos durante o jogo foram analisadas para obtermos uma visão sobre a complexidade das hipóteses e como uma avaliação do jogo.

Quadro 3: Roteiro para a produção textual entregue após a aplicação do jogo “Invade!”.

\section{Projeto "Ensino de invasão biológica utilizando o jogo Invade!"}

Nome:

Serie:

Turma: 
Realize um texto sobre o que você achou do jogo "Invade!" e responda as seguintes perguntas:

- Você acha que o jogo “Invade!” ajudou a entender o conceito de Invasão Biológica? Explique porque ajudou ou porque não ajudou.

- Você tem sugestões para melhorar o jogo? Se tiver sugestões explique.

\section{Fonte: Autora.}

Outro método de coleta de dados que realizamos foi a entrevista aberta grupal. O intuito deste método é avaliar com mais profundidade a produção textual realizada anteriormente pelos participantes. A entrevista também pode ser utilizada para complementar ou esclarecer os dados obtidos por meio de outros métodos previamente utilizados para a coleta de dados (DUARTE, 2004; FRASER et al., 2004; MANZINI, 2004). Assim, as perguntas realizadas foram baseadas no roteiro de produção textual, nos próprios textos produzidos pelos alunos, e questões adicionais realizadas espontaneamente. A entrevista aberta grupal foi analisada seguindo o protocolo de Bauer e Gaskell (2015), que consiste na transcrição da entrevista e construção de uma matriz tema/pergunta versus entrevistado. Identificamos por meio da categorização por rotulação as unidades similares no texto para a observação de padrões nos relatos. Finalmente, juntamos os dados dos textos e da entrevista para realizar uma interpretação global do potencial do jogo no processo de aprendizagem.

Para manter o sigilo na identidade dos alunos que participaram da pesquisa, foram criados códigos. Somente os dados dos alunos que participaram da aplicação do jogo, da produção textual e da entrevista aberta grupal foram utilizados nesta pesquisa. Cada aluno recebeu um código utilizando a letra A e um número em ordem crescente (Ar a A6).

\section{RESULTADOS E DISCUSSÃO}

A aplicação total do jogo "Invade!" aconteceu em duas aulas (2hora/aula) de dias diferentes, por motivos de organização da turma, tempo de explicação das regras e atividades extraclasse dos próprios alunos. A aplicação mostrou que para jogar uma partida inteira são necessárias duas aulas seguidas, o que pode vir a desmotivar alguns docentes a utiliza-lo, no atual contexto escolar. No sistema de ensino por semestralidade adotado na Secretaria de Educação do DF, cada turma estuda o conteúdo de Biologia em um dos semestres do ano (BRASIL, 2018). Dependendo do semestre, a quantidade de feriados e eventos extracurriculares pode acabar diminuindo o tempo de ensino, impedindo de que metodologias de ensino que necessitam de mais tempo de desenvolvimento sejam adotadas. Sugerimos que o jogo seja aplicado junto ao conteúdo de impactos ambientais, já que tem ligação direta com este conteúdo. No entanto, o jogo tem potencial de ser aplicado em outros momentos, como ser na disciplina Parte Diversificada (PD) ou mesmo em atividades extraclasse. O jogo "Invade!" permite uma abordagem interdisciplinar ao tratar sobre contextos históricos e geográficos da introdução das espécies. Dessa forma, parcerias com professores de outras disciplinas podem contribuir na sua aplicação. Assim, o jogo não se limita ao conteúdo de Biologia ou de educação ambiental e pode ser aplicado em outras situações.

\section{Impressões gerais do jogo “Invade!"}

Tanto nos textos produzidos pelos alunos como na entrevista realizada, as impressões sobre o jogo trouxeram aspectos positivos. Nos textos, foi comentado que o jogo é realista ( $\left.\mathrm{A}_{3}\right)$, que foge da rotina da sala de aula, é uma maneira simples de aprender o conteúdo (A4, A2) e foram sujeitos a pensar para resolver os problemas, ajudando assim na "fixação" do conteúdo (A6). Perceberam também que o jogo é autoexplicativo $\left(\mathrm{A}_{3}\right)$ e que ele permite interação entre os jogadores $\left(\mathrm{A}_{4}\right)$.

Já na entrevista, as palavras utilizadas para descrever a experiência vivenciada também foram positivas, tais como: "gostei”, “de boas", "foi divertido", "achei interessante", "bacana”, e "muito legal”. 
Os alunos justificam estas opiniões pelo aspecto interativo do jogo e pelo aprendizado que este proporciona. As impressões gerais sobre o jogo, relatadas na entrevista, apontam também o aspecto lúdico e o aprendizado, como pode ser percebido nas falas que seguem:

"Eu gostei muito do jogo, achei bastante interativo, tem algumas partes que podem melhorar, com certeza tem, mas o jogo em si está muito, mas muito legal mesmo. Eu aprendi bastante coisa com o jogo, não tudo, mas bastante coisa. Deu para ter uma ideia muito melhor disso [...]". (A 1 )

“Bom, eu achei divertido [...]". (A3)

Os comentários mostram que o jogo ajudou no processo de aprendizado sobre a IB. Observamos indícios de que o jogo é um recurso motivador e que aumenta a interação entre os participantes. Lourenço e Paiva (2010) sugerem que a motivação auxilia no processo de aprendizado, uma vez que o aluno se esforça para resolver e desenvolver as habilidades. A interação entre os participantes, por outro lado, é vantajosa ao permitir que o jogo seja realizado de maneira prazerosa (CABRERA, 2007). Porém, é necessário ressaltar que o jogo por si só não garante o aprendizado sobre os conceitos de IB, como observado neste trabalho. A compreensão completa do conteúdo dependerá das atividades complementares que o professor realize após a aplicação.

Quando perguntamos sobre a condução do jogo aos alunos ainda durante a entrevista, a resposta dos seis participantes explicitou a participação dos deles como sujeitos ativos e que o professor foi um simples mediador do processo. Apesar disso, quando afirmamos que o conhecimento gerado pelo jogo foi produzido por eles próprios não houve nenhuma resposta e se manteve um momento de silêncio. Mesmo tendo gerido o jogo completo, os alunos não perceberam seu papel como sujeitos ativos na construção do conhecimento ao jogar. Estimular os alunos a pensar e criticar construtivamente é importante para sua formação como cidadão, porém também é importante que os alunos percebam que o conhecimento pode ser construído por si próprio e não recebido pelo professor (LIBÂNEO, 2011).

Um fator importante na aplicação do jogo e para alcançar seu objetivo, é necessário que os alunos tenham conhecimento prévio sobre a construção de hipóteses, já que o jogo faz uso desse tipo de estratégia. Ao ser um recurso diferente da aula tradicional, os próprios alunos contribuem na organização da turma quando o jogo é aplicado (NICOLA, PANIZ, 2016), permitindo um melhor aproveitamento e a facilitação no processo de aprendizagem do conteúdo.

\section{Hipóteses produzidas na aplicação do jogo "Invade!"}

As hipóteses produzidas durante o jogo demonstraram o potencial do jogo como um contribuidor para o processo de aprendizagem do conceito de IB sem criar preconceitos sobre as EEI. Além de exercitarem a produção científica por meio das hipóteses, os participantes tiveram o primeiro contato com o conceito e a oportunidade de produzir um significado ao fenômeno abordado.

\section{- Transporte}

As hipóteses criadas para atravessar a barreira do transporte se basearam no uso do navio, avião e em um único caso o ser humano. Metade dos grupos (quatro grupos) especificou a razão pela qual o organismo foi transportado e a outra metade especificou somente o meio de transporte. A finalidade do transporte foi, em todos os casos, para fins econômicos, como descrito no gabarito. Um único grupo (Mosquito a) não devolveu a folha com as hipóteses e por isso não foi possível avaliar. Nesta barreira não observamos nenhum erro conceitual ou de formulação da hipótese.

No decorrer da pesquisa, percebemos que o transporte foi o mecanismo que ficou mais esclarecido para os alunos, pois esta barreira foi mencionada em todas as tentativas de conceituar a IB. Apesar de não teremos avaliado as causas pela qual a barreira do transporte foi mais bem 
compreendida do que o resto das barreiras, inferimos que: 1) ao ter sido abordada na primeira aplicação houve um maior envolvimento com esta barreira e 2) é uma barreira simples de ser compreendida. Mesmo não tendo uma resposta concreta, é relevante saber que esta barreira teve maior influência no processo de aprendizado sobre a IB.

\section{- Estabelecimento}

As hipóteses criadas para atravessar a barreira do estabelecimento foram construídas utilizando as cartas de nicho vago, de perturbação e de fuga do predador. Somente um grupo (Mosquito a) especificou como a carta escolhida permitiria o estabelecimento: "[...] Uma pessoa deixou água parada no pneu velho inutilizado, o que foi um local próprio para reprodução”. A hipótese proposta pelo grupo Caramujo a sugere que a espécie atravessa a barreira somente se o ambiente fosse favorável para a sobrevivência, adicionando uma hipótese de sucesso da invasão não presente nas cartas. Os grupos Capim b e Pinheiro b não indicaram a carta utilizada nem a razão pela qual houve o estabelecimento, porém inferimos que escolheram a carta "Pressão de propágulos", pois incluíram conceitos de taxa de reprodução e colonização da espécie. Nenhum equívoco conceitual foi percebido na elaboração dessas hipóteses.

As hipóteses do estabelecimento mostram como os grupos conseguiram juntar os conhecimentos prévios sobre a espécie com as possibilidades apresentadas pelo jogo ou ir além do jogo para realizar a hipótese. Isso mostra que apesar do jogo estar dividido em barreiras o conhecimento é único e não se restringe à estrutura do jogo. Com a possibilidade de extrapolar os conceitos propostos pelo jogo, vemos que há uma aplicação do conhecimento para gerar novos aprendizados. Observamos que foi a barreira menos compreendida, pelo nível de dificuldade nas hipóteses de sucesso de invasão. Mesmo assim, observamos que os alunos levantaram outras possibilidades para criar suas hipóteses, construindo assim, seu próprio conceito de IB de maneira construtivista (LIBÂNEO, 2011).

- Dispersão

As hipóteses criadas para atravessar a barreira de dispersão foram construídas utilizando todas as cartas. Observamos que houve alguns erros conceituais nas hipóteses apresentadas, um deles foi a hipótese do grupo Caramujo a: "Eles são carregados por outros animais até certo local, ou grudam neles, predadores podem impedir o transporte (Biótico)" indicando que esses animais foram dispersos por meio de outros animais. O outro erro aconteceu nos grupos dos Mosquitos ao sugerirem que a dispersão acontece pela capacidade de locomoção individual, o que pode ser percebido nos trechos que seguem:

\footnotetext{
"Em um vento muito forte o mosquito é carregado e assim viaja por longas distâncias." (Mosquito A)
}

"Ele se espalha rapidamente através da água parada. E por conseguir voar em longas distâncias." (Mosquito B).

As hipóteses da dispersão mostram alguns erros conceituais. Um exemplo é a dispersão do caramujo-gigante-africano, na qual poucos animais não humanos poderiam transportá-lo. O caramujo não dispersa por grandes distâncias sem a ajuda do ser humano (ALBUQUERQUE et al. 2008), mostrando que esta hipótese estaria biologicamente equivocada. Outro exemplo de equívoco são as hipóteses criadas pelos grupos dos mosquitos que sugerem que a dispersão acontece pela capacidade de locomoção individual. Sabe-se que a capacidade de locomoção do mosquito é baixa e que esse se dispersa junto ao ser humano (BRASIL, 2001). Apesar de que no jogo, para atravessar a barreira não há necessidade de que a hipótese esteja correta, é importante que aquelas hipóteses que não possuem um embasamento biológico sejam ressaltadas para que os alunos não construam conceitos ou pensamentos errôneos. 
- Impacto

Finalmente, as hipóteses criadas para atravessar a barreira do impacto foram construídas utilizando todas as cartas. O jogo "Invade!" permitiu que os alunos observassem o impacto da espécie por diversos pontos de vista já que não os induziu a pensar em possíveis impactos negativos. O grupo Caramujo a sugeriu que a espécie não causava nenhum impacto, mesmo que na ficha da espécie tivesse a descrição da espécie como vetor de doenças. Quatro grupos (Caramujo b, Capim a, Mosquito a e Mosquito b) sugeriram que a espécie se tornaria invasora ao causar impactos negativos e três grupos (Capim b, Pinheiro a e Pinheiro b) sugeriram que a espécie causa impactos positivos. Os grupos da espécie do Mosquito apresentaram impacto negativo nas duas hipóteses. A hipótese do Caramujo b foi uma cópia da ficha da espécie, entregue ao início do jogo. O Capim a foi o único grupo que criou uma hipótese sobre impacto ambiental: "Ele causa impacto ambiental roubando nutrientes do solo de outras plantas, desfertilizando o solo impedindo novas plantas nascerem”.

Houve uma ligação do ser humano com a espécie nas hipóteses dos grupos que apontaram impactos positivos, pois consideraram o ganho econômico ou a importância sociocultural da espécie, como impacto positivo. O grupo do Pinheiro a sugeriu que a introdução de espécies é vantajosa para a diversidade local e o Pinheiro $b$ adiciona o aspecto afetivo da espécie com o ser humano, além do aspecto econômico. O grupo Capim a afirma que a espécie favorece a economia contradizendo o grupo do Capim b.

As hipóteses do impacto mostram que, para os alunos, esse não necessariamente tem efeito negativo, e que possivelmente, o jogo não induziu um pré-conceito sobre as EEI. Este fato permite que os alunos compreendam que os impactos negativos são o efeito de um processo populacional e não é um fenômeno intrínseco da espécie. As hipóteses refletiram conhecimento popular sobre as espécies, como por exemplo, o pensamento de que o mosquito da dengue é um organismo que somente transmite doença (BRASIL, 2001).

Observamos que a percepção sobre os impactos ambientais foi ignorada pela maioria dos grupos. Proença et al. (2014) sugerem que a falta de interligação entre a origem da espécie com o possível impacto causado é um problema para a o aprendizado na educação ambiental. A falta de associação pode ser vantajosa quando tratamos a IB, pois não dá o papel de vilã à EEI previamente. Porém, mesmo assim é necessário mostrar aos alunos que as EEI são consideradas invasoras por causarem impactos negativos. Por outro lado, os alunos destacaram a relação do ser humano com a EEI quando os grupos as apontaram como causadores de impactos positivos. O jogo "Invade!" permitiu que os alunos observassem o impacto da espécie pelos três pontos de vista já que não induziu a pensar diretamente no impacto negativo. O pensamento de que o impacto pode ser positivo ou negativo depende do ponto de vista ecológico, econômico ou social (SIMBERLOFF et al., 2013). Diante disso, é função do professor regente a introdução de tais pontos de vista com os alunos para mostrar a complexidade e sensibilidade da IB.

A percepção da sociedade sobre o impacto da espécie é de suma importância para os planos de manejo ou erradicação de EEI (BONANNO, 2016). Sugerimos que após a aplicação do jogo, aconteça um debate que ligue os efeitos do triângulo social-econômico-ambiental das EEI. A construção do conceito de IB não tendenciada a um único lado do triângulo permite esclarecer aos alunos a importância de cada lado do triângulo. O jogo cumpriu o requisito de não construir preconceitos nem pensamentos tendenciosos sobre as EEI.

\section{Aprendizado do conceito de IB e dinâmica do jogo}

Os alunos afirmaram que o jogo permitiu a compreensão do conceito de IB de maneira facilitada. Segundo os próprios alunos, a fixação do conteúdo aconteceu de maneira simples e descontraída. Em relação ao conceito de IB, dos seis alunos, somente dois alunos mencionaram aquilo 
que compreenderam sobre a IB: "meios de transporte, proliferação e impacto da espécie no ambiente" (A2) e "conceituar ideias sobre propagação de espécies sobre uma boa parte do mundo" (A1). Ao serem questionados sobre as frases anteriores, os dois alunos explicaram o seguinte:

\begin{abstract}
"A invasão biológica, o que entendi sobre invasão biológica, é que as espécies, elas vêm muitas vezes de outros lugares de onde elas estão acostumadas, e vão se espalhando por outros continentes e países através de viagens, por pessoas, navios, até mesmo pássaros. Às vezes os pássaros pegam algum tipo de espécie, animais, ou até mesmo, como por exemplo, a abelha que pega os polens e vão espalhando. Basicamente isso e aprendi muita coisa sobre isso. Não sei explicar ao certo, mas na minha cabeça é basicamente isso. Ele [o jogo] não ensina completamente sobre tudo, porque não dá pra ensinar tudo. Mas uma boa parte da para aprender com o jogo em si”. (A1)
\end{abstract}

Esse relato mostra como o aluno A1 conseguiu inserir o conhecimento aprendido no jogo na vida real ao tentar explicar o conceito de IB utilizando espécies que não pertencem ao jogo. Apesar de esse conceito dar ênfase somente na barreira do transporte, ele destaca o transporte mediado pelo ser humano e por fatores bióticos. A percepção de que a IB acontece naturalmente também pode ser observada pela citação às abelhas que espalham o pólen, inserindo a possibilidade da dispersão de propágulos. A IB mediada naturalmente não foi mencionada em nenhum momento da aplicação, porém o relato de A1 mostra como inferências além do jogo podem ser realizadas após jogar o "Invade!".

Outro relato que merece destaque é o do aluno A2, que conceituou corretamente o processo da IB e realçou a vantagem de utilizar ferramentas didáticas diferentes das aulas tradicionais:

“Sem falar que é melhor né, dá para aprender mais do que só na sala de aula”. (A2)

O jogo "Invade!" facilitou o processo de aprendizagem por deixar o conteúdo de IB mais palatável e compreensível. Corroboramos assim os diversos estudos que mostram o jogo educativo como ferramenta de ensino eficaz no ensino de conteúdos (PORTUGAL et al., 20o6; CANTO, ZACARIAS, 2009; JORGE et al., 2009; CUNHA, 2012; BELARMINO et al., 2015; BRÃO, PEREIRA, 2015; NASCIMENTO et al., 2015). Nosso estudo mostra que os jogos educativos podem facilitar o aprendizado de conceitos, reforçando as vantagens de utilizar este material no ensino básico como alternativa à aula teórica expositiva (CUNHA, 2012).

O jogo "Invade!" precisa de diversos conhecimentos prévios para ser jogado. Observamos que o jogo pode ser usado como método de revisão de outros conteúdos relacionados, tais como nicho, dispersão, elaboração de hipótese, entre outros. Isto mostra que o jogo "Invade!" coloca em prática o conteúdo de Ecologia, ajudando assim, no aprendizado de outros conceitos além da IB. Além disso, o jogo mostrou seu potencial de ser utilizado como uma ferramenta avaliativa. Os jogos educativos podem ter o potencial de ser uma ferramenta avaliativa do conteúdo (SILVA, AMARAL, 2011). A avaliação do conteúdo utilizando os jogos deve ser realizado cuidadosamente, pois há necessidade de verificar o aprendizado de cada um ao jogar. O jogo "Invade!" pode ser utilizado para avaliar conteúdos de ecologia e a produção de hipótese, permitindo assim um outro uso deste recurso. Essa avaliação pode acontecer pela mediação do professor, observando as hipóteses elaboradas pelos jogadores e em um outro momento comentando-as com a turma. Segundo Hoffman (2003) a avaliação desafia o estudante na reflexão sobre as situações que vive, na formulação e reformulação de hipóteses de forma a encaminha-lo a um saber enriquecido. Cabe, portanto, ao professor realizar esse processo de mediação, junto ao seu aluno, permitindo que o aluno participe, raciocine, compreenda, sendo que o jogo pode ser fundamental para que isso aconteça (FIORENTINI; MIORIN, 1990).

Um aspecto que motivou e facilitou o aprendizado de IB é o aspecto lúdico do jogo. O professor deve procurar, sempre que possível apresentar aos seus alunos, situações de aprendizagem que sejam motivadoras, desafiando-os, pois assim acabam por despertar o interesse pelo que está sendo 
apresentado em sala de aula (KYIA,2014). Alves (2010) destaca que o lúdico auxilia o aprendizado pela associação do desenvolvimento cognitivo com a afetividade. Kiya (2014) afirma que o uso de jogos e de atividades lúdicas, como recursos metodológicos, podem não só tornar o ensino mais agradável, mas também podem ser a saída para melhorar o processo de ensino e de aprendizagem. Ao jogar o indivíduo se socializa, pode formular ideias, elaborar conceitos ou ainda estabelecer relações lógicas (KIYA, 2014). A autora cita ainda que o uso do jogo ou de qualquer outra atividade lúdica utilizada com a intenção de ensinar ou mesmo como mediador da aprendizagem, pode agir como um facilitador desse processo tornando a aprendizagem não só mais cheia de significados como também mais prazerosa. O desenvolvimento de memórias afetivas causado pelo envolvimento emocional com a atividade proposta permite a construção do conhecimento (BALBINOT, 2005). Considerar o jogo divertido pode indicar que houve algum envolvimento emocional com o jogo, logo, com o conhecimento construído nele.

Estimular a competição entre os participantes foi intencional por acreditarmos que poderia ser mais um elemento que aumenta a ludicidade do jogo, porém a competição intraespecífica (grupos com a mesma espécie) não ficou tão evidente e isso pode não ter influenciado no processo de aplicação. Por outro lado, houve competição interespecífica (entre grupos com espécies diferentes). Este estímulo gerado pela competição fez que os alunos se envolvessem mais na produção das hipóteses e consequentemente no processo de aprendizado dos conceitos de IB.

A avaliação das hipóteses demonstrou esta competição interespecífica, pois houve grupos que avaliaram com muita rigidez os outros grupos. Porém, esta rigidez dependia da posição do grupo no tabuleiro e da amizade entre os componentes do grupo. A falta de rigidez na avaliação aconteceu pelos mesmos motivos citados anteriormente. Assim, a competição entre os grupos tanto motivou os estudantes quanto os desmotivou. Melim (2009) sugere que o aspecto lúdico dos jogos didáticos esteja relacionado à cooperação e não pela competição entre os grupos, sendo assim, é mais interessante que seja enfatizada a cooperação para ganhar o jogo. Diante disso, observamos que a competição e a avaliação das hipóteses devem ser mais bem planejadas para não desmotivar os jogadores, incentivando mais a cooperação entre os estudantes.

\section{CONCLUSÃO}

O jogo "Invade!" mostrou-se efetivo no processo de aprendizagem dos alunos em relação ao conceito de IB. Isto corrobora mais uma vez que jogos são recursos de ensino com grande potencial no aprendizado de conteúdos e outras competências, como o trabalho em equipe e desenvolvimento de habilidades. Além disso, seu aspecto lúdico auxilia e aumenta a motivação no processo de aprendizado. Ao não incorporar conceitos enviesados sobre as EEI, verificamos que é possível que os alunos observem as espécies de diversas perspectivas. Assim, o conhecimento gerado no jogo pode ser utilizado futuramente para uma educação com enfoque ambiental, que espera causar mudanças comportamentais.

Algumas das limitações do jogo "Invade!" se relacionam ao o tempo preciso para sua aplicação. Nestes casos, pode ser utilizado na disciplina prática diversificada (PD) ou em atividades extraclasse. Outra limitação é a construção do jogo físico, pois demandou tempo de construção e material de papelaria. Para resolver este problema, formas alternativas de construir o jogo é utilizando materiais presentes na escola e ajuda dos próprios alunos, para que sua utilização em na escola seja viável.

Neste trabalho não avaliamos o aprendizado do conceito de IB, porém, nós observamos que o jogo "Invade!" influenciou no processo de aprendizagem sobre tais conceitos. Consideramos que o jogo é mais um recurso que fomenta o ensino de IB na educação básica. Mostramos com a aplicação deste jogo que é possível ensinar a IB de maneira não tradicional. Sendo assim, quanto mais recursos didáticos sobre este tema forem criados, maior a possibilidade de que docentes da rede pública e particular abordem este tema nas escolas. 


\section{REFERÊNCIAS}

ALbUQUERQUE, F.; PESO-AGUIAR, M. C.; ASSUNÇÃO-AlBUQUERQUE, M. J. T. Distribution, feeding behavior and control strategies of the exotic land snail Achatina fulica (Gastropoda: Pulmonata) in the northeast of Brazil. Brazilian Journal of Biology, v. 68, n. 4, p. 837-842, 2008.

ALVES, L.; BIANCHIN, M. A. O jogo como recurso de aprendizagem. Revista de Psicopedagogia, v. 27, n. 83, p. 282-287, 2010.

ALVES, R. C.; FARIA, M. L. C. DE; COSTA, F. M. DA. Avaliação dos conhecimentos dos alunos sobre a espécie invasora Achatina fulica (Pulmonata, Achatinidae) em uma escola de ensino fundamental de Colorado do Oeste, Rondônia, Brasil. Gaia scientia, v. 11, n. 2, p. 132-143, 2017.

BALBINOT, M. C. Uso de modelos, numa perspectiva lúdica, no ensino de ciências. Em: Anais do IV encontro Ibero-Americano de coletivos escolares e redes de professores que fazem investigação na sua escola. 2005 .

BAUER, M. W.; GASKELL, G. Pesquisa qualitativa com texto, imagem e som: um manual prático. Tradução: Guareschi, P. A. Editora Vozes Limitada, 2015.

BELARMINO, F. S.; DOS SANTOS, C. A.; BALTAR, S. L. S. M. A.; BEZERRA, M. L. M. B. O jogo como ferramenta pedagógica para o ensino de ciências: experiências com o tabuleiro da cadeia alimentar. Em: Anais do Congresso de Inovação Pedagógica em Arapiraca. 2015.

BOAVENTURA, M. F. F.; THIENGO, S. C.; MONTEIRO, S. Infestações por caramujo africano (Achatina fulica): análise de conteúdo das matérias jornalísticas e de materiais educativos sobre o tema no Rio de Janeiro, Brasil. Revista Brasileira de Pesquisa em Educação em Ciências, v. 11, n. 2, p. 9-24, 2011.

BONANNO, G. Alien species: to remove or not to remove? That is the question. Environmental Science \& Policy, v. 59, p. 67-73, 2016.

BRÃO, F. A. S.; PEREIRA, A. M. T. B. Biotecnétika: Possibilidades do jogo no ensino de genética. Revista Electrónica de Enseñanza de las Ciencias, v. 14, n. 1, 2015.

BRASIL. Ministério do Meio Ambiente. Declaração de Tbilisi. 1972.

BRASIL. Ministério da Educação. Secretaria de Educação Básica. Parâmetros Curriculares Nacionais+. Orientações Curriculares para o Ensino Médio: Ciências da natureza, matemática e suas tecnologias. 2000.

BRASIL. Ministério da Educação. Secretaria de Educação Básica. Parâmetros Curriculares Nacionais. 2000.

BRASIL. Ministério da Educação. Secretaria de Educação Básica. Diretrizes para a organização do trabalho pedagógico na Semestralidade: Ensino Médio. 2018.

BRETON, J. LE; CHAZEAU, J.; DEJEAN, A. Niche opportunity and ant invasion: the case of Wasmannia auropunctata in a New Caledonian rain forest. Journal of Tropical Ecology, v. 21, p. 93-98, 2005.

CABRERA, W. B. A ludicidade para o ensino médio na disciplina de biologia: Contribuições ao processo de aprendizagem em conformidade com os pressupostos teóricos da Aprendizagem Significativa, 2006. 159f. Dissertação (Mestrado em Ensino de Ciências e Educação Matemática) - Programa de Pós-Graduação em Ensino de Ciências e Educação Matemática, Universidade Estadual de Londrina, Londrina, 2006.

CANTO, A. R.; ZACARIAS, M. A. Utilização do jogo Super Trunfo Árvores Brasileiras como instrumento facilitador no ensino dos biomas brasileiros. Ciência \& Cognição, v. 14, n. 1, p. 144-153, 2009.

CENTRO EDUCACIONAL o3 DO GUARÁ DF. Centrão do Guará. Disponível em: http://centraoguara.com.br/. Acesso em: 15 de Abril de 2018

CONVENTION ON BIOLOGICAL DIVERSITY. Glossary of terms. Disponível em: https://www.cbd.int/invasive/terms.shtml. Acesso em: 15 de Abril de 2018. 
CUNHA, M. B. Jogos no Ensino de Química: Considerações teóricas para sua utilização em sala de aula. Quimica Nova Na Escola, v. 34, n. 2, p. 92-98, 2012.

DUARTE, R. Entrevistas em pesquisas qualitativas. Educar, v. 24, p. 213-225, 2004.

FIORENTINI, D.; MIORIM, M. A. Uma reflexão sobre o uso de materiais concretos e jogos no ensino da matemática. Boletim da SBEM-SP, v. 4, n. 7, 1990.

FORTUNA, T. R. Jogo em aula: Recurso permite repensar as relações de ensino-aprendizagem. Revista do Professor, v. 19, n. 75, p. 15-19, 2003.

FRASER, M. T. D.; GONDIM, S. M. G. Da fala do outro ao texto negociado: discussões sobre a entrevista na pesquisa qualitativa. Paidéia, v. 14, n. 28, p. 139-152, 2004.

GODOY, O.; CASTRO-DIEZ, P.; VALLADARES, F.; COSTA-TENORIO, M. Different flowering phenology of alien invasive species in Spain: evidence for the use of an empty temporal niche? Plant Biology, v. 11, p. 803-811, 2009.

GROTT, S. C.; MELLO, L. J. Conhecimento sobre o caramujo gigante africano (Achatina fulica, Linnaeus, 1758) entre estudantes de uma escola pública no município de Blumenau SC. Ensino, Saúde e Ambiente, v. 7, n. 2, p. 12-27, 2014.

HIERRO, J. L.; VILLARREAL, D.; EREN, Ö.; GRAHAM, J. M.; CALLAWAY, R. M. Disturbance Facilitates Invasion: The Effects Are Stronger Abroad than at Home. The American Naturalist, v. 168, n. 2, p. 144-156, 2006.

HOFFMANN, J. Avaliação mito e desafio uma perspectiva construtivista. Porto Alegre: Mediação, 2003.

JORGE, V. L.; GUEDES, A. G.; FONTOURA, M. T. S.; PEREIRA, R. M. M. Biologia limitada: um jogo interativo para alunos do terceiro ano do ensino médio. Em: VII Encontro Nacional de Pesquisa em Educação em Ciências, 2009.

KEANE, R. M.; CRAWLEY, M. J. Exotic plant invasions and the enemy release hypothesis. Trends in Ecology and Evolution, v. 17, n. 4, p. 164-170, 2002.

KIYA, M. C. S. O uso de jogos e de atividades lúdicas como recurso pedagógico facilitador da aprendizagem.

Caderno Pedagógico. Secretaria de Estado da Educação - SEED Programa de Desenvolvimento Educacional PDE Universidade Estadual de Ponta Grossa. 2014

KISHIMOTO, T. M. O jogo e a educação infantil. Perspectiva, v. 12, n. 22, p. 105-128, 1996.

LEVINE, J. M.; VILÀ, M.; D`ANTONIO, C. M.; et al. Mechanisms underlying the impacts of exotic plant invasions. Proceedings of the Royal Society of London B, v. 270, p. 775-781, 2003.

LIBÂNEO, J. C. O Essencial Da Didática E O Trabalho De Professor - Em Busca De Novos Caminhos. p. 1-9, 2001.

LOCKWOOD, J. L.; HOOPES, M. F.; MARCHETTI, M. P. Invasion Ecology. United Kingdom, UK: Blackwell Publishing Ltd, p. 304, 2007.

LOURENÇO, A. A.; PAIVA, M. O. A. A motivação escolar e o processo de aprendizagem. Ciências \& Cognição, V. 15, n. 2, p. 132-141, 2010.

MACEDO, L. Os jogos e sua importância na escola. Cad. Pesquisa, São Paulo, n. 93, maio 1995.

MACK, R. N.; LONSDALE, W. M. Humans as global plant dispersers: Getting more than we bargained for. BioScience, v. 51, n. 2, p. 95-102, 2001.

MANZINI, E. J. Entrevista semi-estruturada: análise de objetivos e de roteiros. Em: Seminário internacional sobre pesquisa e estudos qualitativos, v. 2, p. 10, 2004. 
MELIM, L. M. C.; SPIEGUEL, C. N.; ALVES, G. G.; LUZ, M. R. M. P. Cooperação ou Competição? Avaliação de uma estratégia lúdica de ensino de Biologia para estudantes do ensino médio. Em: VII Encontro Nacional de Pesquisa em Educação em Ciências, 2009.

MORAES, R. Análise de conteúdo. Revista Educação, v. 22, n. 37, p. 1-13, 1999.

NASCIMENTO, M. P.; Cruz, A. H. S.; Santos, R. S.; Cintra, L. Jogos Lúdicos como ferramenta didática para o Ensino de Genética e Biologia Molecular. RENEFARA, v. 7, n. 7, p. 250-271, 2015.

NICOLA, J. A.; PANIZ, C. M. A importância da utilização de diferentes recursos didáticos no Ensino de Ciências e Biologia. InFor, v. 2, n. 1, p. 355-381, 2017.

OLIVEIRA, F. S.; LACERDA, C. D.; OLIVEIRA, P. S.; COELHO, A. A.; BIANCONI, M. L. Um jogo de construção para o aprendizado colaborativo de Glicólise e Gliconeogênese. Revista de Ensino de Bioquímica, v. 13, n. 1, p. 45-57, 2015.

PECORA, I. L.; MIRANDA, M. S. Salvando e aprendendo com Megalobulimus. Revista Ciência em Extenção, v. 10, n. 1, p. 72-82, 2014.

PEJCHAR, L.; MOONEY, H. A. Invasive species, ecosystem services and human well-being. Trends in Ecology and Evolution, v. 24, n. 9, p. 497-504, 2009.

PEREIRA, Z. M.; THIENGO, S. C.; MONTEIRO, S. O caramujo africano em contexto escolar: as percepções de estudantes do ensino fundamental e o estuda da helmintofauna associada ao caramujo em Barra do Piraí (RJ). Revista Ensaio, v. 14, n. 3, p. 275-288, 2012.

PORTUGAL, N. Q.; PINTO JÚNIOR, J. E. S.; SILVA, S. A.; PESSANO, E. F. C. Tabuleiro Uru-Aay: um modelo lúdico de aprendizagem sobre o ecossistema do Rio-Uruguai. Em: Anais do Salão Internacional de Ensino, Pesquisa e Extensão, v. 7, n. 3, 2016.

PROENÇA, M. S.; OSLAJ, E. U.; DAL-FARRA, A. R. As percepções de estudantes do ensino fundamental em relação às espécies exóticas e o efeito antrópico sobre o ambiente: uma análise com base nos pressupostos da CTSA - Ciência-Tecnologia-Sociedade- Ambiente. Pesquisa em Educação Ambiental, v. 9, n. 2, p. 51-66, 2014.

PYŠEK, P.; JAROŠÍK, V.; HULME, P. E.; et al. A global assessment of invasive plant impacts on resident species, communities and ecosystems: the interaction of impact measures, invading species' traits and environment. Global Change Biology, v. 18, p. 1725-1737, 2012.

QUEIROZ, R. M.; TERÁN, A. F.; QUEIROZ, A. G. DE. O caramujo africano (Achatina fulica), perigos para a saúde e o meio ambiente: uma proposta de alfabetização ecológica. Ensino, Saúde e Ambiente, v. 7, n. 1, p. 1-12, 2014.

RAMULA, S.; JAUNI, M.; OOIK, T. VAN. Propagule pressure governs establishment of an invasive herb. Acta Oecologica, v. 68, p. 18-23, 2015.

ROMAIS, D. K.; NETO, J. G.; ZENNI, R. D.; RIBEIRO, R. C.; ZILLER, S. R. Resultados Preliminares do Informe Nacional de Espécies Exóticas Invasoras. Ministério do Meio Ambiente, p. 1-9, 2003.

SIMBERLOFF, D.; MARTIN, J. L.; GENOVESI, P.; MARIS, V.; WARDLE, D. A.; ARONSON, J.; COURCHAMP, F.; GALIL, B.; GARCÍA-BERTHOU, E.; PASCAL, M.; PYŠEK, P.; SOUSA, R.; TABACCHI, E.; VILÀ, M. Impacts of biological invasions: what's what and the way forward. Trends in Ecology and Evolution, v. 28, n. 1, p. 58-66, 2013.

SILVA, T. C.; AMARAL, C. L. C. Jogos e avaliação no processo ensino-aprendizagem: uma relação possível. Revista de Ensino de Ciências e Matemática, v. 2, n. 1, p. 1-8, 2011.

SOUZA, R. M. DE; ALVES, Â. C. G.; ALVES, M. S. Conhecimento sobre o molusco gigante africano Achatina fulica entre estudantes de uma escola pública na Região Metropolitana do Recife. Biotemas, v. 20, n. 1, p. 81-89, 2007. 
ZENNI, R. D.; DECHOUM, M. D. S.; ZILLER, S. R. Dez anos do informe brasileiro sobre espécies exóticas invasoras: avanços, lacunas e direções futuras. Biotemas, v. 29, n. 1, p. 133-153, 2016.

Waira Saravia Machida: Graduanda em Biologia pela Universidade de Brasília (UnB). Atualmente é estagiária do laboratório de Anatomia Comparativa de Vertebrados do departamento de Ciências Fisiológicas (CFS) do Instituto de Biologia (IB) - UnB.

E-mail:wsmbio@gmail.com

Hilton de Jesus dos Santos: Possui graduação em Ciências Biológicas pela Universidade de Brasília (2017). Tem experiência na área de Educação, com ênfase em ensino de ciências, atuando principalmente nos seguintes temas: audiovisuais, vídeos educativos, motivação, ensino médio e videoprocesso.

E-mail: hiltonhjs@gmail.com

Ana Júlia Pedreira: Graduada em Ciências Biológicas pela UFV (Universidade Federal de Viçosa), Especialista em Educação à distância, Mestre em Ecologia e Doutora em Educação pela UnB (Universidade de Brasília). Docente na Educação Básica por 18 anos e atualmente professora na UnB no Núcleo de Educação Científica (NECBio) / Instituto de Biologia, atuando nas seguintes áreas: ensino de Ciências, ensino de Biologia, formação de professores e recursos didáticos.

E-mail: anajuliapedreira@unb.br 